\title{
The use of a semiochemical bait to enhance exposure of Amblyomma variegatum (Acari: Ixodidae) to Metarhizium anisopliae (Ascomycota: Hypocreales)
}

\author{
F. Nchu ${ }^{\text {a, b }}$, N.K. Maniania ${ }^{a}$, A. Touréa ${ }^{a}$ A. Hassanali ${ }^{a}$ and J.N. Eloff ${ }^{b}$ \\ ${ }^{a}$ International Centre of Insect Physiology and Ecology (icipe)-African Insect Sciences for Food \\ and Health, P.O. Box 30772-00100 GPO Nairobi, Kenya \\ ${ }^{b}$ Programme for Phytomedicine, Department of Paraclinical Sciences, University of Pretoria, \\ Private Bag X 04 Onderstepoort 0110, South Africa
}

\begin{abstract}
Experiments were conducted to explore the use of a semiochemical bait to enhance exposure of Amblyomma variegatum Fabricius (Acari: Ixodidae) to different formulations of the entomopathogenic fungus Metarhizium anisopliae (Metsch.) Sorok. (Ascomycota: Hypocreales). Initially, the relative efficacies of attraction-aggregation-attachment pheromone (AAAP), made up of o-nitrophenol, methyl salicylate and nonanoic acid in the ratio 2:1:8, 1-octen-3-ol and butyric acid, were evaluated in an olfactometer. Only AAAP and 1-octen-3-ol were found to elicit attractive responses to the tick. Simultaneous release of 1-octen-3-ol and AAAP together with $\mathrm{CO}_{2}$ from a trap in semifield plots attracted up to $94.0 \pm 6 \%$ of adult ticks from a distance of $6 \mathrm{~m}$, and up to $24.0 \pm 5.1 \%$ from $8 \mathrm{~m}$. Formulations of $M$. anisopliae (dry powder, oil, and emulsifiable) applied within the trap baited with AAAP, 1-octen-3-ol and $\mathrm{CO}_{2}$ resulted in high levels of contamination of the ticks attracted to the traps. However, $48 \mathrm{~h}$ after autoinoculation, 89.1 and $33.3 \%$ of conidia were lost in dry powder and oil formulations, respectively.

Emulsifiable formulation showed least loss of propagules (17.1\%). Samples of ticks attracted to the baited traps were transferred to plastic basins containing grass and maintained for 5 weeks. The experiment was conducted in rainy and dry seasons. Emulsifiable formulation gave the highest relative tick reduction in both seasons: 54.7 and $46.5 \%$ in rainy and dry seasons, respectively, followed by oil formulation (32.0 and 23.8\%) and powder formulation (38.0 and $24.4 \%)$.
\end{abstract}

Keywords: Entomopathogenic fungus; Metarhizium anisopliae; Semiochemical-baited trap; Amblyomma variegatum; Autoinoculation

\section{Introduction}

Amblyomma variegatum Fabricius 1794 (Acari: Ixodidae) or the tropical bont tick is the most widely distributed tick species across the African continent (Walker et al., 2003) and was recently introduced into the Caribbean (Barré et al., 1995). It transmits Ehrlichia ruminantium (Rickettsiales: Anaplasmataceae), a rickettsia that causes heartwater in ruminants, and the bacterium Dermatophilus congolensis van Saceghem 1915 (Actinobacteria: Dermatophilaceae), an acute bovine dermatophilosis. A. variegatum is also a vector of Rickettsia africae Kelly et al. (1996) sp. nov. (Rickettsiales: Rickettsiaceae), the causative agent of African tick-bite fever (Morita et al., 2004). Although endemic to sub-Saharan Africa (Kelly et al., 1996), the disease is spreading rapidly and is regarded as the most widely distributed of all rickettsial spotted fever known to be pathogenic to humans (Raoult and Roux, 1997). Infestation by ticks can also cause 
considerable losses in the livestock industry in Africa and the Caribbean (Uilenberg et al., 1984 and Kavaria, 2006).

Current methods of tick control rely heavily on conventional chemical acaricides and repellents. These are faced with numerous setbacks including rapid tick resistance to these synthetic chemicals, negative impact on human health and environmental contamination (Mukhebi and Perry, 1992, George, 2000, Jonsson et al., 2000 and Tingle et al., 2000). This has prompted the search for alternative methods of tick control that can be used in combination with other tick control methods in an integrated tick management strategy (Jongejan, 1998). These include the use of nematodes, tick semiochemicals, entomopathogenic fungi and combination of both semiochemical and entomopathogenic fungi (Samish and Rehacek, 1999, Kaaya and Hassan, 2000 and Maranga et al., 2006). (Maranga et al., 2005) and (Maranga et al., 2006) reported a reduction of the $A$. variegatum tick population in experimental field plots following application of the mitosporic entomopathogenic fungi Metarhizium anisopliae (Metsch.) Sorok. and Beauveria bassiana (Bals.) Vuill. (Ascomycota: Hypocreales). Norval et al. (1996) and Allan et al. (1998) also reported significant reduction of Amblyomma tick population on cattle using tail tags impregnated with pheromones and acaricides.

Amblyomma ticks respond to a number of semiochemicals including the attraction-aggregationattachment pheromone (AAAP) emitted by feeding males and carbon dioxide (kairomone) exhaled from their hosts (Sonenshine, 2006). A device baited with the pheromone for infecting Amblyomma ticks with entomopathogenic fungi in the field was first described by Maranga et al. (2006). However, the device is costly to fabricate and difficult to use. This may discourage their possible wider use. Therefore, there is need to develop a simple low-cost contamination device or modify the existing one. Bryson et al. (2000) developed an easy device for tick monitoring. The device, which uses solvent extracts of fed-male ticks as baits could be adopted. The attraction of ticks to the trap could be increased by optimization of the pheromone AAAP and carbon dioxide. The chemical 1-octen-3-ol, which occurs naturally in adult $A$. variegatum and is a minor constituent of cattle breathe, has been reported to be attractive to $A$. variegatum adults in the laboratory (McMahon et al., 2001). Butyric acid, a constituent of rumen metabolites of vertebrates has also been reported to elicit tick attraction in the laboratory (Donzé et al., 2004). The objectives of the present study were (i) to see if 1-octen 3-ol and butyric acid would augment the AAA pheromone in the attraction of $A$. variegatum adults; (ii) to test the performance of the trap described by Bryson et al. (2000) baited with a synthetic combination of effective semiochemicals; and (iii) to compare the performance of fungal formulations that could be used with semiochemical-baited trap for effective control of $A$. variegatum in the field.

\section{Materials and methods}

\subsection{Tick}

Engorged $A$. variegatum females used to start the colony originated from cattle from the Marsabit area of Kenya in 2006. Ticks were reared at the Animal Rearing and Quarantine Unit, International Centre of Insect Physiology and Ecology (icipe). All life stages of the tick were fed on New Zealand white rabbits. The different instars were maintained in perspex chambers at $26 \pm 1{ }^{\circ} \mathrm{C}$ and $85 \pm 5 \% \mathrm{RH}$ under 12:12 L:D photoperiod. Three to four-week old unfed adults were used in this study. 


\subsection{Fungus}

M. anisopliae (isolate R1/RA, accession no ICIPE 07) used in this study was obtained from the icipe Arthropod Germplasm Centre. The strain was isolated from an engorged female $A$. variegatum collected from Rusinga Island, Kenya in 1996 and was previously reported to be virulent against $A$. variegatum. The fungus was stored under mineral oil before being used in the experiment. The virulence of the isolated fungus was restored by passage through adult $A$. variegatum. Conidia were produced on long rice as substrate using Milner's bag process (Milner R.J., unpubl.). Viability of conidia was determined using the technique described by Goettel and Inglis (1997) before conidia could be used for field experiment. Conidial germination above $90 \%$ was obtained and was considered suitable for field application.

\subsection{Source of semiochemical candidates}

The synthetic components of attraction-aggregation-attachment pheromone (ortho-nitrophenol, methyl salicylate and nonanioc acid), dicloromethane (DCM), butyric acid and 1-octen-3-ol were obtained from Sigma-Aldrich Chemie GmbH, Steinheim, Germany. Dry ice used as a source of $\mathrm{CO}_{2}$ was obtained from Carbacid Kenya.

\subsection{Optimization of semiochemical blend}

A two-choice T-tube olfactometer bioassay method was used to assess tick attraction to one out of two odour sources. The olfactometer was made of two cubicle glass arms $\left(1 \mathrm{~cm}^{3} \times 10 \mathrm{~cm}\right.$ length) and a stem $\left(1 \mathrm{~cm}^{3} \times 5 \mathrm{~cm}\right.$ length $)$ connected tightly. The extreme end of the arms and stem was connected to a cubicle glass chamber $\left(3 \mathrm{~cm}^{3}\right)$. The chamber of the stem served as the release point. Air entered each arm of the olfactometer and flowed over the respective odour source filter paper $\left(2 \mathrm{~cm}^{2}\right)+$ pheromone and/or kairomones or control in the chamber at a flow rate of $5 \mathrm{ml} / \mathrm{s}$. The concentrations of semiochemicals in DCM solvent on the test filter paper that were evaluated for attraction are presented in Table 1. Control filter paper had DCM only. One tick was inserted in the release chamber at a time and had to move upwind as in nature. Each tick was allowed a minimum of $0.5 \mathrm{~s}$ and a maximum of $5 \mathrm{~min}$ to decide. Tick failing to respond was removed. For each replicate one randomly selected tick was bioassayed separately. Twenty ticks (10 males and 10 females) were successfully assayed for each dose. The olfactometer was cleansed with DCM and air dried at $40{ }^{\circ} \mathrm{C}$ for $10 \mathrm{~min}$ after each bioassay. Treatment and control chambers at the end of the arm were alternated after every assay by alternating control and test filter papers. The olfactometer was placed horizontally during the experiment. Ticks were used only once. The experiment was conducted at $26 \pm 1{ }^{\circ} \mathrm{C}$ and $70 \pm 5 \% \mathrm{RH}$. 
Table 1. Concentrations of semiochemicals that were evaluated in T-tube olfactometer.

\begin{tabular}{|l|l|l|l|l|}
\hline Semiochemicals & \multicolumn{4}{ll}{ Concentration } \\
\hline AAA $^{\mathrm{a}}$ & $1.1 \mathrm{mg}$ & $0.044 \mathrm{mg}$ & $0.022 \mathrm{mg}$ & $0.0147 \mathrm{mg}$ \\
\hline Butyric acid & $10 \mathrm{ng}$ & $1 \mathrm{ng}$ & $0.5 \mathrm{ng}$ & - \\
\hline 1-Octen-3-ol & $32 \mathrm{ng}$ & $16 \mathrm{ng}$ & $8 \mathrm{ng}$ & - \\
\hline
\end{tabular}

${ }^{\mathrm{a}}$ AAAP $=$ o-nitrophenol, methyl salicylate and nonanoic acid in the ratio 2:1:8.

\subsection{Attraction of ticks to semiochemical-baited trap in experimental field plots}

A modification of the trap described by Bryson et al. (2000) was used in this study. It consisted of a $900-\mathrm{cm}^{2}$ area made of four $10-\mathrm{cm}$ wooden pegs hammered to the ground. A $2-\mathrm{cm}^{2}$ rubber sponge impregnated with $16 \mathrm{ng}$ of 1-octen-3-ol and $0.022 \mathrm{mg}$ of AAAP was fixed on the top of each of the four wooden pegs per trap. These concentrations were selected following the results obtained in T-tube olfactometer bioassays. Blocks of dry ice (approx. $70 \mathrm{~g}$ ) in a plastic beaker in the centre of the trap served as $\mathrm{CO}_{2}$ source. Traps were placed upwind on the chosen sites to allow ticks to move upwind. Open areas $\left(225 \mathrm{~m}^{2}\right)$ with $5-\mathrm{cm}$ high grass were considered suitable for the traps. Test and control traps were placed $2 \mathrm{~m}$ from each other. Ticks were placed at 1, 2, 3, 4, 5, 6, 7 and $8 \mathrm{~m}$ downwind from the traps at an angle of $90^{\circ}$ midway between the test and control traps. Ten ticks (five males and five females) were used for each distance. Ticks were given distinct colour spot by painting with artist's paint (Rowney Geogian oil colour, made in England, London HA $35 \mathrm{RH}$ ) applied topically and ventrally depending on their distance from the trap. The experiment was conducted from 13 to 30 October 2006 within icipe's Nairobi Headquarters premises and was allowed to run for $90 \mathrm{~min}$ in mornings between 08:00 and 09:30 h. The experiment was replicated five times. The temperature above ground during the experimental period ranged between 25 and $29^{\circ} \mathrm{C}$ (under the sun) and the relative humidity between 50 and $70 \%$.

\subsection{Efficacy of fungal formulation on tick reduction in the field}

Three formulations of fungal spores were evaluated in the semiochemical-baited trap described above:

(i) Dry powder spores (approx. $50 \mathrm{~g}$ ) spread on the grass within the trap by hand.

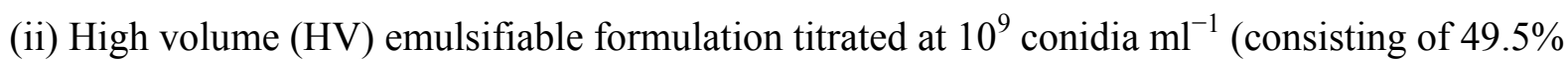
sterile distilled water, 49.5\% corn oil CHEF cooking oil, Premier Oil Mills Ltd. and 1\% Tween 80 ). Two hundred and fifty millilitres was sprayed within the trap using a sprayer (C 1.5 model) at an output of $150 \mathrm{l} / \mathrm{ha}$.

(iii) An ultra-low volume (ULV) oil formulation at $1 \times 10^{9}$ conidia $\mathrm{ml}^{-1}$. Hundred millilitres was sprayed using a Micron-ULV sprayer (Micron Sprayers, Bromyard, UK) at the output of $11 /$ hectare. 
(iv) Control treatments consisted of the same formulations without fungus, except in the case of dry conidia.

After the treatments were completed, 24 ticks were placed at $4 \mathrm{~m}$ away from the traps. Ticks were attracted to the pheromone-baited trap where they got contaminated with fungus. Ticks were then transferred from the trap to plastic basins $(41 \mathrm{~cm}$ top diameter $\times 29 \mathrm{~cm}$ bottom diameter $\times 24 \mathrm{~cm}$ height) previously planted with Pennisetum clandestinum (kikuyu grass). The height of the grass was approximately $12 \mathrm{~cm}$. The top of the basin was sealed with mosquito net (supplied by Amiran Kenya) using rubber bands to prevent ticks for escaping. The experiment was allowed to run for 5 weeks, after which the number of ticks was recorded. Ticks that survived infection in the field were transferred to 9-cm diameter Petri dish and brought to the laboratory where they were maintained at $26 \pm 1{ }^{\circ} \mathrm{C}, 85 \pm 5 \% \mathrm{RH}$ and 12:12 h L:D photoperiod for 2 weeks, after which mortality was recorded. Ticks were observed for mortality after 2 weeks. Dead ticks were surface-sterilized with $2.5 \%$ sodium hypochlorite and $70 \%$ alcohol, and rinsed twice in sterile distilled water. They were then placed into 9-cm diameter Petri dish lined with moistened filter paper to favour development of mycosis on the surface of the cadaver. Petri dishes were sealed with paraffin and maintained at room temperature $\left(25 \pm 2{ }^{\circ} \mathrm{C}\right)$. Five plastic basins were used for each treatment, which represented five replicates. The experiment was repeated two times: from September to October 2007 and from December 2007 to January 2008, which corresponded to rainy and dry seasons, respectively. The average daytime range of temperatures and relative humidity within buckets for first trial were $24.8 \pm 0.7-29.3 \pm 0.5^{\circ} \mathrm{C}$ and $86.3 \pm 2.4-89 \pm 1.8 \%$, respectively. The average daytime range of temperatures and relative humidity were $25.0 \pm 0.3-$ $27.4 \pm 0.2{ }^{\circ} \mathrm{C}$ and $53.5 \pm 3.4-66.4 \pm 3.4 \%$, respectively, for the second trial.

\subsection{Effect of fungal formulation in contaminating ticks}

The objective was to estimate the number of conidia that a single tick picked up while visiting the semiochemical-baited trap immediately after treatment and $48 \mathrm{~h}$ after they were transferred to the grass into the plastic basins. Four ticks per replicate and per treatment were selected at random and each was transferred separately into $10-\mathrm{ml}$ vial and brought to the laboratory. Vials were filled with $5 \mathrm{ml} 0.05 \%$ Triton X-100 and subjected to vigorous shaking by a vortex shaker $5 \mathrm{~min}$ to dislodge conidia from the tick surface. The number of conidia was determined using the improved Neubauer counting chamber. The treatment consisted of five replicates of four ticks each and the experiment was repeated twice.

\subsection{Data analysis}

The percentage attraction in T-tube assays was determined using the following formula: (number of ticks in test - number of ticks in control)/(number of ticks in control + number of ticks in test) $\times 100$. The significance of difference in proportion of ticks (males and females pulled) attracted to test and control treatments amongst different concentrations was determined by Fisher's exact method at $P=0.05$ (Robertson, 1960). One-way ANOVA was performed on arcsin-square root transformed tick control efficacy (\%) data, arcsin square root transformation of percentage attraction of $A$. variegatum in the field, arcsin square root transformation of tick mortality $(\%)$ in the laboratory and $\log$ base $10(\times)$ transformations of mean number of spores on ticks. The means were separated by Tukey (HSD) test using the SAS (2001) package at $P=0.05$. The relative tick reduction (\%) in traps baited with semiochemicals and the three fungal formulations was calculated using the formula (number of alive ticks in control - number of alive ticks in test)/number of alive ticks in control × 100 (European Medicines Agency, 2004). 


\section{Results}

\subsection{Optimization of semiochemical blend}

In olfactometer bioassays, AAAP at the concentrations of $0.0147,0.022$ and $0.044 \mathrm{mg}$, and 1octen-3-ol at the concentration of $16 \mathrm{ng}$ attracted both sexes of $A$. variegatum. However, the tick significantly $(P<0.05)$ avoided AAAP at the concentration of $1.1 \mathrm{mg}$ in the olfactometer assay (Table 2). Butyric acid repelled unfed $A$. variegatum ticks (Table 2).

Table 2. Percentage relative attraction of Amblyomma variegatum adults (pooled data for males and females) to semiochemicals in a two-choice olfactometer.

\begin{tabular}{|l|l|}
\hline Semiochemical & \% Relative attraction \\
\hline AAAP & \multicolumn{2}{|l|}{} \\
\hline $1.1 \mathrm{mg}$ & $-50^{\mathrm{a}}$ \\
\hline $0.044 \mathrm{mg}$ & 20 \\
\hline $0.022 \mathrm{mg}$ & 50 \\
\hline $0.0147 \mathrm{mg}$ & 30 \\
\hline Butyric acid & \\
\hline $10 \mathrm{ng}$ & -20 \\
\hline $1 \mathrm{ng}$ & -20 \\
\hline $0.5 \mathrm{ng}$ & -10 \\
\hline $1-$ Octen-3-ol & \\
\hline $32 \mathrm{ng}$ & -30 \\
\hline $16 \mathrm{ng}$ & 50 \\
\hline $8 \mathrm{ng}$ & 20 \\
\hline
\end{tabular}

${ }^{a}$ Denotes attractive response was significantly different compared to the other concentrations for each semiochemical within column at $P<0.05$.

\subsection{Attraction of adult $A$. variegatum to semiochemical-baited trap in field plots}

No single tick moved to the control trap (No AAAP, carbon dioxide and 1-octen-3-ol) in the field. Ticks were attracted from up to a distance of $8 \mathrm{~m}$ (Table 3). No significant difference was observed in the attraction of groups of ticks released between 1 and $6 \mathrm{~m}$ away from the trap. However, fewer ticks were attracted to the semiochemical-baited trap beyond $6 \mathrm{~m}$. There was no 
significant difference $(P>0.05)$ in the attraction between males and females to the blend. We observed that some ticks spent several seconds within the trap before leaving, whilst others showed arrestant behavior.

Table 3. Attraction of adult A. variegatum (pooled data for males and females) to trap baited with a blend of AAA pheromone at concentration of $0.022 \mathrm{mg}, 1$-octen-3-ol at concentration of $16 \mathrm{ng}$ and $\mathrm{CO}_{2}$ in field condition.

\begin{tabular}{|l|l|}
\hline Distance (m) & Percentage (mean \pm S.E.) tick attraction \\
\hline 1 & $100 \pm 0 \mathrm{a}$ \\
\hline 2 & $100 \pm 0 \mathrm{a}$ \\
\hline 3 & $96 \pm 2.5 \mathrm{a}$ \\
\hline 4 & $100 \pm 0 \mathrm{a}$ \\
\hline 5 & $96 \pm 2.5 \mathrm{a}$ \\
\hline 6 & $94 \pm 6 \mathrm{a}$ \\
\hline 7 & $66 \pm 5.1 \mathrm{~b}$ \\
\hline 8 & $24 \pm 5.1 \mathrm{c}$ \\
\hline
\end{tabular}

Mean tick attraction between distances $(F=36.4$; d.f. $=7,32 ; P<0.0001)$. Means within column bearing the letter are not significantly different at the 0.05 level as determined with Tukey's test.

\subsection{Efficacy of fungal formulation on tick reduction in the field}

Emulsifiable conidial formulation caused significant $(P<0.05)$ tick reduction $(54.7 \%)$ compared to powder formulation (38.0\%) and oil formulation (32.0\%) during the first trial conducted in the rainy season; however, no significant difference was obtained between powder and emulsifiable formulation. In the second trial conducted in the dry season, emulsifiable formulation also caused significant $(P<0.05)$ tick reduction $(46.5 \%)$ compared to powder $(24.4 \%)$ and ULV oil $(23.8 \%)$ formulations (Table 4). Ticks that survived infection in the field succumbed to fungal infection 2 weeks after they were moved to the laboratory: 46.8 and 53.0\% mortality in emulsifiable formulation, first and second trial, respectively; 39 and 34.4\% in oil formulation, first and second trial, respectively; 4.2 and $6.8 \%$ in powder formulation, first and second trial, respectively. 
Table 4. Percent relative tick reduction (mean \pm S.E.) of formulations of Metarhizium anisopliae applied in pheromone-baited trap against $A$. variegatum during the first and second trial over the controls.

\begin{tabular}{|l|l|l|}
\hline Formulation & (\%) Relative tick reduction (mean \pm S.E.) \\
\hline & First trial & Second trial \\
\hline Powder & $38.0 \pm 6.2 \mathrm{ab}$ & $24.4 \pm 3.9 \mathrm{~b}$ \\
\hline High volume (HV emulsifiable) & $54.7 \pm 4.2 \mathrm{a}$ & $46.5 \pm 5.5 \mathrm{a}$ \\
\hline ULV oil & $32.0 \pm 5.1 \mathrm{~b}$ & $23.8 \pm 3.3 \mathrm{~b}$ \\
\hline
\end{tabular}

Mean relative tick reduction during the first trial $(F=4.94$; d.f. $=2,12 ; P=0.02)$ and second trial $(F=8.47$; d.f. $=2,12 ; P=0.005)$. Means bearing the same letter within column are not significantly different at the 0.05 level as determined with Tukey's test.

\subsection{Effect of fungal formulation in contaminating ticks}

No significant differences $(P>0.05)$ were observed between the treatments in the first and second trials (data pooled). The number of conidia picked by individual ticks immediately after the treatment was significantly higher $(P<0.05)$ in powder formulation

$\left(6.7 \times 10^{6} \pm 8.4 \times 10^{5}\right.$ conidia $)$, followed by emulsifiable formulation

$\left(4.6 \times 10^{5} \pm 5.7 \times 10^{4}\right.$ conidia $)$ and oil formulation $\left(2.3 \times 10^{5} \pm 2.3 \times 10^{4}\right.$ conidia) (Table 5). However, $48 \mathrm{~h}$ postinfection, ticks in powder formulation had fewer conidia, representing a significant $(P<0.05)$ loss of $89.1 \%$ compared to $17.1 \%$ and $33.3 \%$ with emulsifiable $(P>0.05)$ and oil $(P<0.05)$ formulations, respectively (Table 5$)$.

Table 5. Mean ( $X \pm$ S.E.) number of spores recorded on ticks immediately after contamination (day 0) and 2 days postinfection in pheromone trap. Data of two experiments were pooled.

\begin{tabular}{|l|l|l|l|}
\hline Formulation & $\begin{array}{l}\text { Mean }(\boldsymbol{X} \pm \text { S.E.) }(\text { day } \\
\mathbf{0})\end{array}$ & $\begin{array}{l}\text { Mean }(\boldsymbol{X} \pm \text { S.E. })(\text { day } \\
\text { 2) }\end{array}$ & $\begin{array}{l}\text { Spore loss } \\
(\%)\end{array}$ \\
\hline Powder & $67 \times 10^{5} \pm 8.4 \times 10^{5} \mathrm{aA}$ & $73 \times 10^{4} \pm 6.5 \times 10^{4} \mathrm{aB}$ & 89.1 \\
\hline $\begin{array}{l}\text { High volume (HV } \\
\text { emulsifiable) }\end{array}$ & $46 \times 10^{4} \pm 5.7 \times 10^{4} \mathrm{bA}$ & $37 \times 10^{4} \pm 4.2 \times 10^{4} \mathrm{bA}$ & 17.1 \\
\hline ULV oil & $23 \times 10^{4} \pm 2.3 \times 10^{4} \mathrm{cA}$ & $15 \times 10^{4} \pm 3.0 \times 10^{4} \mathrm{cB}$ & 33.3 \\
\hline
\end{tabular}

Mean number of spores picked by individual tick at day 0 and day 2 in powder $(F=106.6$; d.f. $=1,78 ; P<0.0001)$, oil $(F=14.49$; d.f. $=1,78 ; P<0.0003)$ and emulsifiable $(F=0.35$; d.f. $=1,78 ; P=0.55)$ formulations. Means bearing the same lowercase letter within column and uppercase letter within row are not significantly different at the 0.05 level as determined with Tukey's test. 


\section{Discussion}

AAAP attracted unfed adults of $A$. variegatum in laboratory assays as previously reported (Schoni et al., 1984 and Touré, 2005). Schoni et al. (1984) found the activity threshold of the synthetic AAAP in laboratory assays to correspond to an equivalent of $10^{-2}$ fed-male-extract, which represents a summation of the amounts of the three components produced by one fed adult male of $A$. variegatum $(2 \mu \mathrm{g}$ o-nitrophenol, $1 \mu \mathrm{g}$ methyl salicylate and $8 \mu \mathrm{g}$ nonanoic acid corresponding to the ratio $2: 1: 8$ ). In this study, the olfactometer was placed horizontally, which is consistent with the natural hunter behavior of host seeking A. variegatum and optimum attraction was recorded at $0.022 \mathrm{mg}$ of AAAP (Table 2). Higher doses of AAAP appeared to be avoided by the tick. Previously, Touré (2005) reported attraction at a higher dose $(1.1 \mathrm{mg})$ in a T-tube olfactometer placed vertically. Response to an attractant varies with its ambient concentration gradients; for example, A. variegatum ticks were reported to be insensitive to high levels of 1octen-3-ol but were attracted to lower levels (McMahon and Guerin, 2000).

Of the two additional candidate semiochemicals evaluated in the laboratory in this study, butyric acid appeared to be repellent to unfed $A$. variegatum ticks at the three concentrations tested and was not included in semifield experiments. High attraction responses of $A$. variegatum adults to 1-octen-3-ol observed in this study was in agreement with that reported by McMahon et al. (2001) and Touré (2005). In field plots, Touré (2005) also recorded enhanced attraction of $A$. variegatum to a combination of 1-octen-3-ol and AAAP. In the present study, the combination

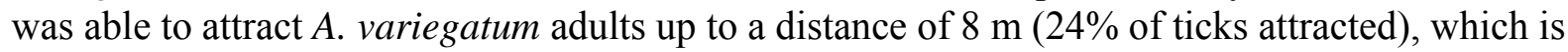
further than those reported in previous studies, where ticks were attracted to a maximum distance of 5 or $6 \mathrm{~m}$ and with less efficiency (Barré et al., 1997 and Maranga et al., 2003). Maranga et al. (2003) used $6.6 \mathrm{mg} /$ trap of AAAP to elicit optimum attraction of A. variegatum without 1-octen3 -ol in the field. This dose of AAAP far exceeded the dose of $0.088 \mathrm{mg} /$ trap (equivalent to eight fed-male ticks per trap) that was used in the current study in field plots. The fact that adults of $A$. variegatum were lured from $8 \mathrm{~m}$ and congregated within the baited-trap in our study, demonstrates the efficacy of the combination of AAAP and 1-octen-3-ol (0.088 mg and $64 \mathrm{ng}$, respectively) used in the present study in field plots. 1-Octen-3-ol is a significant constituent of cattle odour (Osterkamp et al., 1999). Thus, observed enhancement in the attraction of $A$. variegatum adults resulting from its inclusion with AAAP is not surprising.

Although the ticks that were attracted to traps with $M$. anisopliae powder treatment initially picked the highest number of spores $\left(6.7 \times 10^{6} \pm 8.4 \times 10^{5}\right.$ conidia) compared to oil and emulsifiable formulations of the fungus $\left(2.3 \times 10^{5} \pm 2.3 \times 10\right.$ and $4.6 \times 10^{5} \pm 5.7 \times 10^{4}$ conidia, respectively), this treatment also led subsequently to the highest spore loss $(89.1 \%) 48 \mathrm{~h}$ posttreatment. Fungal formulations that are electrostatically charged or have lipophylic charateristics may enhance the adherence of conidia on the cuticle of the tick and thereby offer better control. This requires further research. In the present study, the emulsifiable formulation caused higher reduction in tick numbers (54.7 and $46.5 \%$ in the rainy and dry season, respectively) than the others. Maranga et al. (2006) recovered 33.8\% of A. variegatum ticks released in plots that had semiochemical-baited trap with a mixture of $B$. bassiana and $M$. anisopliae in oil-based formulation compared to $76.3-84.1 \%$ in control plots. 
Oil is known to enhance adhesion between propagules and hydrophobic cuticle (Prior et al., 1988). The difference in the relative tick reduction between emulsifiable and oil formulations in this study could partially be explained by the fact that spray droplets released under pressure from HV application had better penetration into the grass than ULV oil formulation. Ekesi et al. (1998) reported similar results with $M$. anisopliae against the flower trips, Megalurothrips sjostedti (Trybom) and attributed it to better penetration by the infective propagules as a result of the large volumes applied to the plant.

In summation, the present study demonstrates the potential of semiochemical-baited trap for delivery of entomopathogenic fungi for control of Amblyomma spp. This strategy could be valuable for reducing Amblyomma population around water points, camping sites and paddock facilities. Further studies are required to validate these results in large-scale field experiments.

\section{Acknowledgements}

The authors wish to thank the SII-Netherlands for funding this project via a fellowship awarded through the African Regional Postgraduate Program in Insect Science (ARPPIS) administered by icipe. We also acknowledge the technical assistance of Ms. Elizabeth Ouna and Mr. Richard Rotish.

\section{References}

Allan et al., 1998 S.A. Allan, N. Barré, D.E. Sonenshine and M.J. Burridge, Efficacy of tags impregnated with pheromone and acaricide for control of Amblyomma variegatum, Med. Vet. Entomol. 12 (1998), pp. 141-150.

Barré et al., 1995 N. Barré, G. Garris and E. Camus, Propagation of the tick Ambyomma variegatum in the Caribbean, Rev. Off. Int. Epizoot. 14 (1995), pp. 841-855.

Barré et al., 1997 N. Barré, G.I. Garris and O. Lorvelac, Field sampling of the tick Amblyomma variegatum (Acari: Ixodidae) on pastures in Guadeloupe: attraction of $\mathrm{CO}_{2}$ and/or tick pheromones and conditions of use, Exp. Appl. Acarol. 21 (1997), pp. 95-108.

Bryson et al., 2000 N.R. Bryson, I.G. Horak, E.H. Venter and C.E. Yunker, Collections of freeliving nymphs and adults of Amblyomma hebraeum (Acari: Ixodidae) with pheromones/carbon dioxide traps at 5 different ecological sites in heartwater endermic regions of South Africa, Exp. Appl. Acarol. 24 (2000), pp. 971-982.

Donzé et al., 2004 G. Donzé, C. McMahon and P.M. Guerin, Rumen metabolites serve ticks to exploit large mammals, J. Exp. Biol. 207 (2004), pp. 4283-4289.

Ekesi et al., 1998 S. Ekesi, N.K. Maniania, K. Ampong-Nyarko and I. Onu, Potential of the entomopathogenic fungus, Metarhizium anisopliae (Metsch.) Sorokin for control of the legume flower thrips, Megalurothrips sjostedti (Trybom) on cowpea in Kenya, Crop Prot. 17 (1998), pp. $661-668$. 
European Medicines Agency, 2004 European Medicines Agency, 2004. Guideline on specific efficacy requirements for ectoparasiticides in cattle. EMEA/CVMP/625/03/Final. London. United Kingdom.

George, 2000 J.E. George, Present and future technologies for tick control, Ann. N. Y. Acad. Sci. 916 (2000), pp. 583-588.

Goettel and Inglis, 1997 M.S. Goettel and G.D. Inglis, Fungi: hyphomycetes. In: L.A. Lacey, Editor, Manual of Techniques in Insect Pathology, Academic Press, San Diego (1997), pp. $211-$ 249.

Jongejan, 1998 F. Jongejan, Integrated control of ticks and tick-borne diseases (ICTTD), Parasitol. Today 14 (1998), pp. 173-176.

Jonsson et al., 2000 N.N. Jonsson, D.G. Mayer and P.E. Green, Possible risk factors on Queensland dairy farms for acaricide resistance in cattle ticks, Vet. Parasitol. 88 (2000), pp. 79 92.

Kaaya and Hassan, 2000 G. Kaaya and S. Hassan, Entomogenous fungi as promising biopesticides for tick control, Exp. Appl. Acarol. 24 (2000), pp. 913-926.

Kavaria, 2006 F.M. Kavaria, Estimated direct economic costs associated with tick-borne diseases on cattle in Tanzania, Trop. Anim. Health Prod. 38 (2006), pp. 291-299.

Kelly et al., 1996 P.J. Kelly, L. Beati, P.R. Mason, L.A. Matthewman, V. Roux and D. Raoult, Rickettsia africae sp. nov., the etiological agent of African tick bite fever, Int. J. Syst. Bacteriol. 46 (1996), pp. 611-614.

Maranga et al., 2003 R.O. Maranga, A. Hassanali, G.P. Kaaya and J.M. Mueke, Attraction of Amblyomma variegatum (ticks) to the attraction-aggregation-attachment-pheromone with or without carbon dioxide, Exp. Appl. Acarol. 29 (2003), pp. 121-130.

Maranga et al., 2005 R.O. Maranga, G.P. Kaaya, J.M. Mueke and A. Hassanali, Effects of combining the fungi Beauveria bassiana and Metarhizium anisopliae on the mortality of the tick Amblyomma variegatum (Ixodidae) in relation to seasonal changes, Mycopathologia 159 (2005), pp. 527-532.

Maranga et al., 2006 R.O. Maranga, A. Hassanali, G.P. Kaaya and J.M. Mueke, Performance of a prototype baited trap in attracting and infecting the tick Amblyomma variegatum Acari: Ixodidae) in field experiments, Exp. Appl. Acarol. 38 (2006), pp. 211-218.

McMahon et al., 2001 C. McMahon, P.M. Guerin and Z. Syed, 1-Octen-3-ol isolated from bont ticks attracts Amblyomma variegatum, J. Chem. Ecol. 27 (2001), pp. 471-486.

McMahon and Guerin, 2000 C. McMahon and P.M. Guerin, Responses of the tropical bont tick, Amblyomma variegatum (Fabriscius), to its aggregation-attachment pheromone presented in an air stream on a servosphere, J. Comp. Physiol. A 186 (2000), pp. 95-103. 
Morita et al., 2004 C. Morita, A.R.M. El Hussein, E. Matsuda, K.M. Abdel Gabbar, A.

Muramatsu, M.B. Abdel Rahman, A.M.H. Eleragi, S.M. Hassan, A.M. Chitambo and H. Ueno, Spotted fever group ricketsiae from ticks captured in Sudan, Jpn. J. Infect. Dis. 57 (2004), pp. 107-109.

Mukhebi and Perry, 1992 Mukhebi, A.W., Perry, B.D., 1992. In: Kategile, J.A., Mubi, S. (Eds), Economic Implications of the Control of East Coast Fever in Eastern, Central and Southern Africa. Proceedings of the Workshop held in Kadoma Hotel, Zimbabwe, July 20-23 1992. International Livestock Centre for Africa (ILCA), Addis Ababa, Ethiopia. http://0www.fao.org.innopac.up.ac.za/Wairdocs/ILRI/x5485E/x5485e0h.htm.

Norval et al., 1996 R.A.I. Norval, T. Peter, C.E. Yunker, D.E. Sonenshine and M.J. Burridge, Efficacy of pheromones-acaricides-impregnated tail-tag decoys for controlling the bont tick Amblyomma hebraeum (Acari:Ixodidae) on cattle in Zimbabwe, Exp. Appl. Acarol. 20 (1996), pp. 31-46.

Osterkamp et al., 1999 J. Osterkamp, U. Wahl, G. Schmalfuss and W. Haas, Host-odour recognition in two tick species is coded in a blend of volatiles, J. Comp. Physiol. A 185 (1999), pp. 59-67.

Prior et al., 1988 C. Prior, P. Jollands and G. Le Patourel, Infectivity of oil and water formulations of Beauveria Bassiana (Deuteromycotina; Hyphomycetes) to cocoa weevil pest Pantorhytes plutus, J. Invertebr. Pathol. 52 (1988), pp. 66-72.

Raoult and Roux, 1997 D. Raoult and V. Roux, Rickettsioses as paradigms of new or emerging infectious diseases, Clin. Microbiol. Rev. 10 (1997), pp. 694-719.

Robertson, 1960 W.H. Robertson, Programming Fisher's exact method of comparing two percentages, Technometrics 2 (1960), pp. 103-107.

Samish and Rehacek, 1999 M. Samish and J. Rehacek, Pathogens and predators of ticks and their potential in biological control, Ann. Rev. Entomol. 44 (1999), pp. 159-182.

SAS, 2001 SAS Institute (4th edition), SAS/STAT User's Guide: Version 6 vol. 1, SAS Institute, Cary, NC, USA (2001).

Schoni et al., 1984 R. Schoni, E. Hess, W. Blum and K. Ramstein, The aggregation-attachment pheromone of the tropical bont tick Amblyomma variegatum Fabricius (Acari: Ixodidae): isolation, identification and action of its components, J. Insect Physiol. 30 (1984), pp. 613-668.

Sonenshine, 2006 D.E. Sonenshine, Tick pheromones and their use in tick control, Ann. Rev. Entomol. 51 (2006), pp. 557-580.

Tingle et al., 2000 Tingle, C.C.D., Rother, C.F., Dewhurst, S., Lauer, S., King, W.J., 2000. Health and environmental effects from fipronil. Briefing paper. Pesticide Action Network UK. Briefing Al1 (http://www.pan-uk.org/Publications/Briefing/fipronil.pdf). 
Touré, 2005 Touré, A., 2005. An assessment of the use of botanical extracts and pheromones for the off- and on-host control of Amblyomma variegatum. A thesis submitted in partial fulfillment of the requirements for the degree of Doctor of Philosophy in Veterinary Entomology in the school of pure and applied sciences of Kenyatta University, Kenya.

Uilenberg et al., 1984 G. Uilenberg, N. Barré, E. Camus, M.J. Burridge and G.I. Garris, Heartwater in the Caribbean, Prev. Vet. Med. 2 (1984), pp. 255-267.

Walker et al., 2003 Walker, A.R., Bouattour, A. Camicas, J.-L., Estrada-Peña, A. Horak, I.G., Latif, A.A., Pegram, R.G., Preston P.M., 2003. Ticks of domestic animals in Africa: a guide to identification of species. Bioscience Reports, Edingburgh, 44-66 pp. 